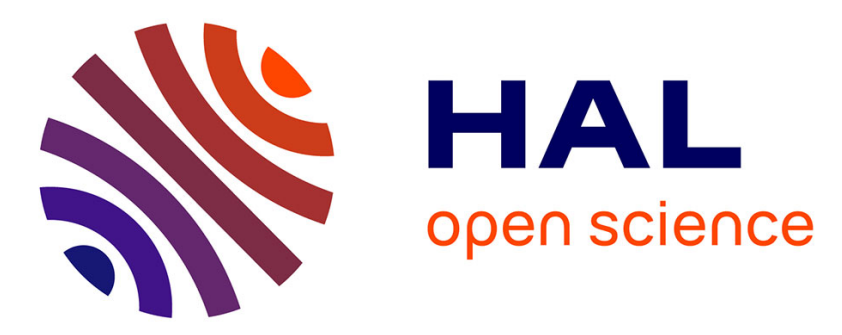

\title{
Social flexibility and environmental unpredictability in African striped mice
}

\author{
Carsten Schradin, Neville Pillay, Cleo Bertelsmeier
}

\section{To cite this version:}

Carsten Schradin, Neville Pillay, Cleo Bertelsmeier. Social flexibility and environmental unpredictability in African striped mice. Behavioral Ecology and Sociobiology, 2019, 73, pp.94. 10.1007/s00265019-2707-7 . hal-02169668

\section{HAL Id: hal-02169668 https://hal.science/hal-02169668}

Submitted on 15 Sep 2020

HAL is a multi-disciplinary open access archive for the deposit and dissemination of scientific research documents, whether they are published or not. The documents may come from teaching and research institutions in France or abroad, or from public or private research centers.
L'archive ouverte pluridisciplinaire HAL, est destinée au dépôt et à la diffusion de documents scientifiques de niveau recherche, publiés ou non, émanant des établissements d'enseignement et de recherche français ou étrangers, des laboratoires publics ou privés. 


\section{The evolution of intra-specific variation in social organization}

2

3 Published as

4 Schradin, C., Pillay, N. \& Bertelsmeier, C. 2019. Social flexibility and environmental 5 unpredictability in African striped mice. Behavioral Ecology and Sociobiology, $6 \quad 73,94$.

9 Carsten Schradin ${ }^{1,2, *}$, Neville Pillay ${ }^{2}, \&$ Cleo Bertelsmeier ${ }^{4}$

$10{ }^{1}$ Université de Strasbourg, CNRS, IPHC UMR 7178, F-67000 Strasbourg, France

$11{ }^{2}$ School of Animal, Plant and Environmental Sciences, University of the Witwatersrand,

12 South Africa.

$13{ }^{3}$ Department of Biology, Geology, and Environmental Sciences, University of Tennessee at

14 Chattanooga, Chattanooga, Tennessee, USA

$15{ }^{4}$ Department of Ecology and Evolution, University of Lausanne, Switzerland.

16

$17 \quad$ *arsten.schradin@iphc.cnrs.fr

18

19 Keywords phenotypic flexibility; phenotypic plasticity; intra-specific variation in social 20 organization; alternative reproductive tactic; extrinsic factors; environmental disrupters; 


\section{Abstract}

Many species show intra-specific variation in their social organization (IVSO), which means the composition of their social groups can change between solitary living, pair-living or living in groups. Understanding IVSO is important because it demonstrates species resilience to environmental change and can help us to study ultimate and proximate reasons for groupliving by comparing solitary and group-living individuals in a single species. It has long been realized that the environment plays a key role in explaining the occurrence of IVSO. IVSO is expected to have evolved in variable environments and can thus be a key adaptation to environmental change. It has previously been shown that four different mechanisms relying on the environment exist that can lead to IVSO: environmental disrupters, genetic differentiation, developmental plasticity, and social flexibility. All four mechanisms depend on the environment such that focusing only on environmental factors alone cannot explain IVSO. Importantly, only three represent evolved mechanisms, while environmental disrupters leading to the death of important group members induce non-adaptive IVSO. Environmental disrupters can be expected to cause IVSO even in species where IVSO is also an adaptive response. Here we focus on the questions of why IVSO occurs and why it evolved. To understand IVSO at the species level it is important to conduct continuous long-term studies to differentiate between non-adaptive and adaptive IVSO. We predict that IVSO evolves in environments that vary in important ecological variables, such as rainfall, food availability, and population density. IVSO might also depend on life history factors, especially longevity. IVSO is predicted to be more common in species with a short lifespan and that breed only for one breeding season, being selected to respond optimally to the prevailing environmental situation. Finally, we emphasise the importance of accounting for IVSO when studying social evolution, especially in comparative studies, since not every species can be assigned to one single form of social organization. For such comparative studies, it is important to have reliable data-bases based on the primary literature. 
52 Formerly, it was assumed that every species has a specific social system and deviations from it were regarded as abnormal or noise. However, it has been recognized that each of the three components of a species social system (Kappeler \& Schaik 2002) can vary within the species (Lott 1984; Lott 1991): i.e. its mating system (who mates with whom), its social structure (how individuals interact with each other), and its social organization (whether they are solitary, pair-living or living in groups of different composition). Most information is available for the social organization of species. The social organization can affect the social structure and the mating system, influencing the entire social system. Intra-specific variation in social organization (IVSO) during breeding occurs when a species shows two or more of the following forms of social organization (Lott 1991; Schradin 2013): living solitarily, in pairs, one breeding male with several breeding females, one breeding female with several breeding males, or multi-male multi-female groups. Each form of social organization must be composed of breeding individuals, not only dispersing solitary individuals or bachelor groups. Variation in group-size and optimal group size are important topics in behavioral ecology (Markham \& Gesquiere 2017), but, following our definition, do not indicate IVSO if the relative numbers of breeders of each sex does not change.

IVSO occurs in several taxa, including insects and vertebrates. For example, burying beetles (Nicrophorus vespilloides) can be solitary, form pairs or communal groups with two or more breeding females (Eggert 1992), depending on the size of the carrion for which they compete, with more beetles associating at larger carrion (Müller et al. 2006). Similarly, pied kingfishers (Ceryle rudis) can live in pairs, in family groups with philopatric adult offspring, or in polygynous groups, depending on the availability of good nesting sites (Reyer 1980; Reyer 1984). The house mouse (Mus musculus) can live solitarily, in pairs or in communal groups, with resource availability modifying the intensity of intra-specific competition (intrasexual aggression in males and female infanticide) (Latham \& Mason 2004; Berry et al. 2008). 
77 Dunnocks (Prunella modularis) also show varying forms of social organization to maximize

78 individual fitness (Davies 1992), which was used as a model system to study the evolution of

79 sexual conflict, mating systems, parental effort and life histories (Burke et al. 1989; Davies et

80 al. 1996). Male and female dunnocks can change their mating system (monandry, polygyny

81 and polyandry) and social organization (pairs, one female and several males, or multi male

82 multi female groups). In a series of sophisticated experiments, including measuring individual

83 fitness, it was demonstrated that IVSO is the consequence of individual dunnocks choosing

84 the reproductive tactic with the highest fitness depending on the prevailing ecological 85 conditions (Davies 1992).

86 To understand IVSO, it is not sufficient to study the related environmental factors.

87 Tinbergen proposed in his four questions that behavior must be understood from the

88 perspectives of ontogeny, causation, phylogeny and function (Tinbergen 1963), and the

89 environment plays a crucial role in all four questions (Schradin 2018). Physiological

90 mechanisms are evolved traits (Hofmann et al. 2014) and thus to understand why IVSO

91 evolved, one must understand the mechanisms leading to IVSO. Thus, the first step to

92 understand why IVSO occurs is to describe and differentiate the mechanisms of IVSO.

93 After summarizing a previous review on IVSO (Schradin 2013), we outline three

94 important new aspects. First, we show the importance of differentiating between adaptive and

95 non-adaptive IVSO. Second, we focus on the questions of why IVSO occurs and why it

96 evolved. Third, we show the importance of accounting for IVSO when studying social

97 evolution, particularly in comparative studies. Finally, we summarise hypotheses and

98 predications about the evolution of IVSO. Our major aim is thus to encourage more research

99 on evolutionary reasons of IVSO and to emphasise the importance of considering IVSO in

100 comparative studies. 


\section{The four mechanisms that can lead to IVSO}

104 In a 2013 review, Schradin proposed four different mechanisms that can lead to IVSO, each

105 mechanism depending on environmental factors (Schradin 2013): environmental disrupters

106 (entirely extrinsic factors), genetic differentiation, developmental plasticity, and social

107 flexibility. Environmental disrupters occur when natural mortality due to old age or predation

108 changes the social organization, which represents a non-adaptive change imposed on the

109 group. IVSO is thus not caused by the remaining individuals which will respond to this new

110 situation with adaptive tactics. This is discussed in detail below. Genetic differentiation refers

111 to the possibility that sub-populations of one species might differ genetically which could

112 influence the resulting social organization. By genetic differences we refer to heritable

113 differences of the genome (for behavior see (Hu \& Hoekstra 2017) for social behaviors

114 (Bendesky et al. 2017); (Dochtermann et al. 2015), which includes not only differences in

115 genes and alleles, but also differences in genomic regions that regulate gene expression.

116 However, while genetic differences between populations of the same species could explain

117 the occurrence of IVSO, evidence for this process is rare to absent. The best example could be

118 fire ants (Solenopsis invicta) which have two social forms (polygynous with several breeding

119 females and monogynous with one breeding female) and it is a single polymorphism at the

120 locus Gp-9 that determines the social organization of a colony. Queens that are homozygous

$121 \mathrm{BB}$ at this locus attempt to found a colony alone, while $\mathrm{Bb}$ and bb queens do not fly far but

122 attempt to join a colony (Gotzek \& Ross 2007; Gotzek \& Ross 2009; Keller 2009; Ometto et

123 al. 2011). Future studies might reveal more examples where genetic differentiation could

124 explain IVSO, but to date empirical evidence does not indicate that it is a common

125 mechanism of IVSO.

126 IVSO can be caused by phenotypic plasticity. Non-reversible phenotypic plasticity is

127 called developmental plasticity, depending on organizational effects during early development

128 (Phoenix et al. 1959; West-Eberhard 2003) or puberty (Zimmermann et al. 2017). In 
developmental plasticity, the environment determines which one of two or more alternative

130 phenotypes develops. If the social behavioral phenotype is permanently influenced during

131 early development, the social organization of this population could differ either from

132 generation to generation, or compared to another population, in both cases leading to IVSO.

133 However, to date there is no empirical evidence that developmental plasticity causes IVSO;

134 yet, future studies might reveal species in which developmental plasticity causes IVSO.

135 Social flexibility, i.e. reversible phenotypic plasticity (Piersma \& Drent 2003) of

136 individual social tactics, is the best empirically documented mechanism leading to IVSO.

137 Flexibility in social behavior is common, because individuals have to respond flexibly

138 depending on the social situation. In primates, flexible dominance hierarchies enable

139 individuals to cope with conflict, enabling them to remain in their group even if new conflict

140 arises (Judge 2000). This is an important social ability in many obligatory group-living

141 species, in which living solitarily is very costly and leads to increased mortality. Individuals

142 flexibility in social behavior stabilizes the social system including the social organization of

143 the species, which can explain why social organization in primates is very stable (Shultz et al.

144 2011). In social species where individuals are less flexible in their social response, alternative

145 and reversible social tactics might exist. Therefore, social flexibility leading to IVSO might be

146 particularly common in species with low flexibility in social behavior, while flexibility in

147 social behavior can maintain the existing social organization. Flexibility in social tactics in

148 both sexes can change the social organization of the entire population. This mechanism is

149 called social flexibility (Schradin et al. 2012) and has been shown to cause IVSO in burying

150 beetles (Eggert 1992; Müller et al. 2006), pied kingfishers (Reyer 1980; Reyer 1984), house

151 mice (Latham \& Mason 2004; Berry et al. 2008), great gerbil (Rhombomys opimus; (Randall

152 et al. 2005) and African striped mice (Rhabdomys pumilio; Schradin et al. 2012).

153 Schradin (2013) identified that for all four possible mechanisms, the environment

154 plays a critical role. Thus, to understand which mechanism is at play, it is not sufficient to 
155 study the environmental factors. One must also establish whether the underlying physiological

156 mechanisms are genetically determined, organizational, or activational (Table 2 in Schradin, 157 2013). In accordance with Piersma \& Gils (2011), Schradin (2013; Table 2) hypothesized that

158 the predictability of the environment will determine which mechanism evolved such that: (i)

159 genetic differentiation evolves in predictable environments (two or more populations with

160 different but predictable environments); (ii) developmental plasticity occurs in short-term,

161 predictable environments (the individual can predict from the environment in which it grows

162 up the environment in which it will breed); and (iii) social flexibility evolves in unpredictable

163 environments. As environmental disrupters do not represent an evolved mechanism of IVSO,

164 it is also not associated to a specific physiological mechanisms nor a specific environment

165 (Schradin 2013).

166

167 How to recognize the different mechanisms?

168 Schradin (2013) identified two questions one needs to answer to show which one of the four

169 mechanisms explains an observed IVSO (Table 3 and 4 in Schradin 2013). 1. Does IVSO

170 occur within or between individuals? This differentiates between genetic variation and

171 developmental plasticity (IVSO between individuals) on the one hand and entirely extrinsic

172 factors and social flexibility on the other (IVSO occurs within individuals). 2. If IVSO occurs

173 between individuals, to differentiate between genetic variation and developmental plasticity

174 one would have to answer the question 'to what extent does the genotype or the environment

175 determine the social tactics shown by individuals? If IVSO occurs within individuals, one has

176 to (i) establish whether the environment induces changes in individual behavior which in turn,

177 leads to a new form of social organization (social flexibility), or (ii) whether the social

178 organization is changed due to one (or more) individuals disappearing (environmental 179 disrupters).

180 


\section{$181 \quad$ IVSO can be non-adaptive}

182 Environmental disrupters are common reasons of IVSO but do not represent an adaptation,

183 but a case where a change in social organization is imposed on the individuals by the

184 environment. If an important group member dies, the social organization of the entire group

185 might change (Fig. 1). For example, in pair-living species, if one of the two breeders dies, the

186 other individual automatically becomes solitary living (Fig. 1). The death of a single

187 individual in pair-living Scandinavian wolves often results in temporarily solitary individuals

188 (Milleret et al. 2017). Individuals might then respond adaptively to this imposed change, such

189 as by re-pairing as reported in beavers (Castor fiber; (Mayer et al. 2017). In pair-living

190 species where the offspring remain in their natal family after reaching adulthood and help in

191 raising their younger siblings, the death of one of the two breeders often leads to reproductive

192 conflicts between the adult non-breeders, which can lead to several forms of social

193 organization. For example, cooperatively breeding callitrichid primates reportedly show

194 considerable IVSO, which has been typically interpreted as an adaptive strategy (Garber 1997;

195 Garber et al. 2016). However, IVSO in callitrichids is often induced by the disappearance of a

196 dominant breeder, for example a breeding male in Goeldi's monkeys (Callimico goeldii)

197 (Porter et al. 2001), in black faced lion tamarins (Leontopithecus caissara) (Martins et al.

198 2015), or in mustached tamarins (Saguinus mystax) (Löttker et al. 2007). In these examples,

199 the changes in social behavior observed in the remaining individuals can be regarded as

200 adaptive, since each individual attempted to optimize its fitness under the new social

201 conditions and to obtain a breeding position. However, the observed IVSO itself was not

202 caused by the individuals. IVSO due to environmental disrupters therefore seems to be very

203 common. 


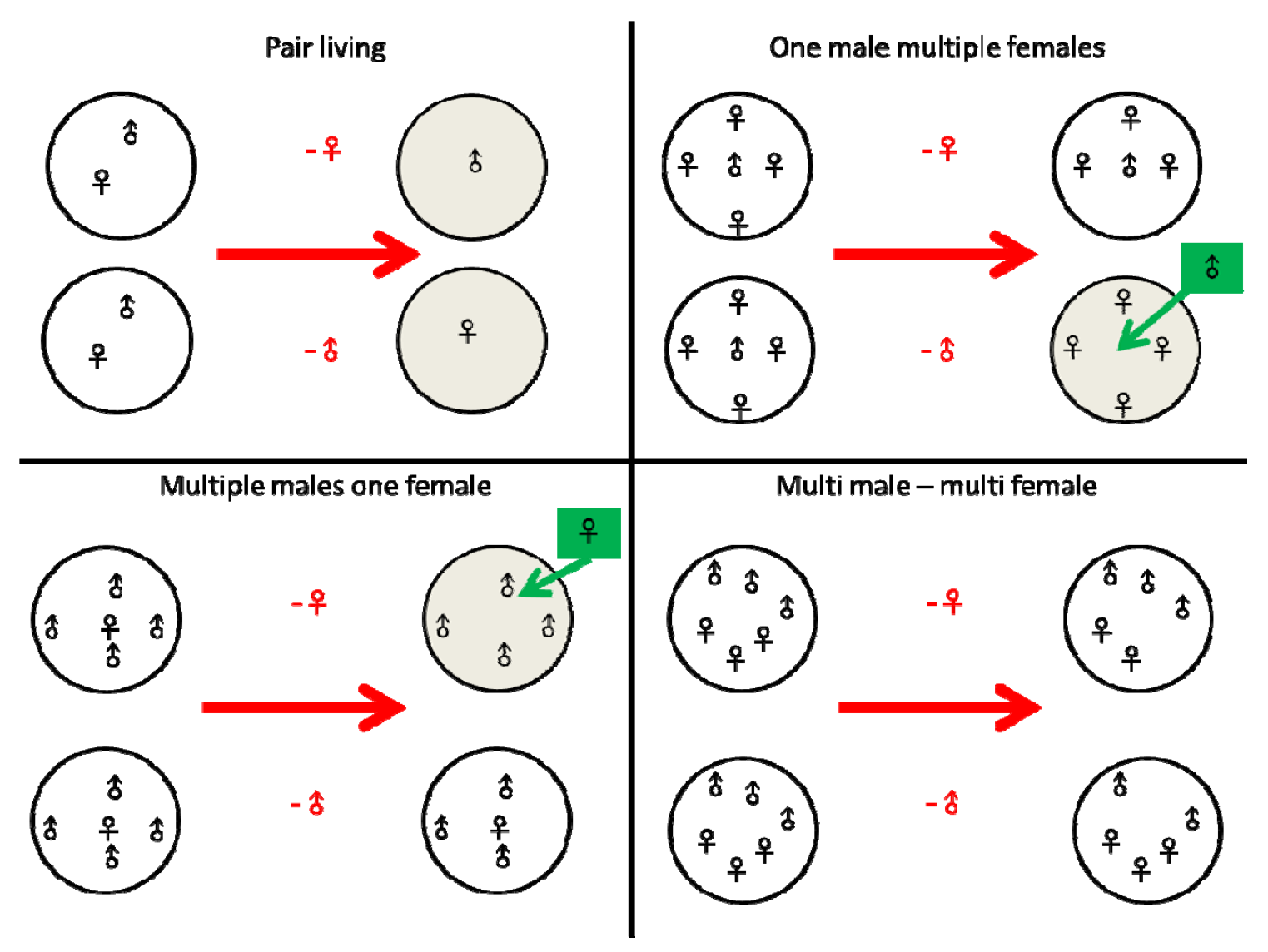

Fig. 1

Mortality of a single individual (indicated by a red arrow and red sex specific symbol) can change the social organization if there is no other breeding individual of the same sex in the group (indicated in grey). This is especially the case in pair-living species (top left), but not in species living in multi-male multi-female groups (bottom right). In species where groups typically consist of only one individual of one sex and multiple individuals of the other sex, mortality of only the individual of the rarer sex changes the social organization (one male multi female groups top right, and multiple males one female groups bottom left). However, in these species, often the vacant breeding position is taken over very quickly (for example from males in bachelor groups), such that no IVSO might be observed (green insets). Note that pair-living species often have groups that also contain adult non-breeders, for example in cooperatively breeding species such as wolves and callitrichids. In these species, mortality of a dominant breeder typically leads to conflict between the remaining group members about who will become a breeder.

It is important to know whether the observed IVSO is due to an environmental disrupter or due to the adaptive choice of individuals. In facultative group-living African striped mice, solitary breeding in females has been described as an adaptive tactic to avoid reproductive competition within groups (Schradin et al. 2010). However, long-term studies revealed that solitary breeding in female striped mice could be the result of two alternative 
mechanisms: 1 . females leaving the communal group to become solitary breeders, indicating an individual choice; or 2 . females becoming solitary breeders because all other females of their group have disappeared, probably due to predation (Hill et al. 2015a). This difference in mechanisms is also represented in differences between females, with solitary females that left the group having a higher body mass and lower corticosterone levels than females that remained in the group, whereas females that became solitary due to environmental disrupters did not differ from group-living females in body size or hormonally (Hill et al. 2015a; Hill et al. 2015b). However, females that chose to become solitary differed significantly in body mass and in hormone levels from females that became solitary due to environmental disrupters (Hill et al. 2015a; Hill et al. 2015b). Thus, to understand the proximate mechanisms and ultimate consequences of solitary breeding, it is important to know whether solitary breeding has been caused by an environmental disrupter or by adaptive individual choices.

\section{The importance of long-term field studies with continuous monitoring}

Identifying IVSO is challenging, especially for long-lived species. It requires long-term field studies (Hayes \& Schradin 2017) which are difficult to initiate and sustain (Schradin \& Hayes 2017). The history of the group must be known for an extended period of time to identify whether changes in social organization are the result of individual choices, indicating adaptive IVSO, or due to environmental disrupters changing the group organization. Thus, long-term field studies must contain continuous observations over several years, not just several extended field trips to the same field site over a few years. This is in contrast to many projects, which are typically funded for only three years, with periods between study years when no field data are collected, and when important members of the study population might disappear for then unknown reasons (Porter et al. 2001). While it is easy to provide adaptive interpretations to explain the observed IVSO, whether or not it is really adaptive or the consequence of environmental disrupters remains unknown. It is important to be aware that 
cases of non-adaptive IVSO due to environmental disrupters can also occur in species where

251 adaptive IVSO occurs, as was demonstrated in the case of solitary breeding in African striped

252 mice (Hill et al. 2015b).

253

\section{Why did IVSO evolve?}

255 Regarding the evolution of IVSO, one can ask several questions. 1. Which environmental

256 factors lead to the evolution of IVSO? 2. How do environmental factors differ between the

257 three described adaptive mechanisms? 3. Which life history traits are related to the evolution 258 of IVSO?

259

IVSO may represent an adaptive response to spatio-temporal variation in environmental conditions (Table 1). Accordingly, stable social organizations can be expected in stable or predictable environments. Such social stability is beneficial because all forms of

262 phenotypic plasticity have costs such as gathering the correct information to decide which 263 phenotype to develop, costs of nervous system tissue to make fitness-enhancing decisions 264 (e.g., dispersal vs. natal philopatry), the risk of developing the wrong phenotype, and the time cost to change (for reviews see (VanBuskirk \& Steiner 2009; Auld et al. 2010; Piersma \& Gils 2011). To avoid these costs, having a stable social organization might be the optimal solution

267 for species evolving in stable or predictable environments. However, if the costs and benefits 268 of social stability differ between sexes (Ebensperger et al. 2016), inter-sexual conflict could 269 facilitate changes in social organization within populations. IVSO might be expected in 270 species that have large geographical ranges encompassing very different environments. 271 Variation in ecological conditions between populations could lead to genetic differentiation 272 affecting the social system and thus IVSO between populations. This could be the starting 273 point of speciation (Meynard et al. 2012; Rymer et al. 2013; Nonaka et al. 2015).

274 Adaptive phenotypic plasticity within populations, including IVSO, can evolve in 275 environments that are variable (Table 1). For an adaptive response to evolve, this variation 
must be repeatable in different generations. For example, IVSO could evolve in environments

277 characterized by repeated, predictable environmental disrupters resulting in periods of high

278

279

280

and low availability of resources, such as periodic El Niño-Southern Oscillation (ENSO) events (Zabel \& Taggart 1989; Dickman et al. 2010). Any given ENSO cannot be predicted precisely, but it is predictable that ENSO will occur again in the future. Thus, animals that evolved in areas where ENSOs occur experience periodic but predictable variation, to which IVSO could be an adaptation (Zabel \& Taggart 1989; Dickman et al. 2010).

Variation in population density may drive IVSO as it influences the availability of breeding territories (habitat saturation hypothesis: (Emlen 1982; Koenig et al. 1992). For example, the social organization of striped mice in the Succulent Karoo is mainly dependent on population density, with solitary living occurring in generations experiencing low population density and communal breeding in generations experiencing high population density (Schradin et al. 2010). Whether developmental plasticity or social flexibility evolves in varying environments would then depend on the predictability of this variation. For developmental plasticity, the environment in which an individual grows up must contain reliable (predictable) information about the environment in which it will breed. In this case, the individual could develop an alternative phenotype via developmental plasticity with the highest reproductive success occurring in the future environment.

\section{Table 1}

Environmental conditions under which the four mechanisms leading to IVSO are predicted to evolve. Predictability can occur within generations (i.e., early and later life of an individual) or between generations (i.e., conditions experienced by adults and their offspring).

\begin{tabular}{|l|l|}
\hline Mechanisms for IVSO & $\begin{array}{l}\text { Environmental conditions under which it is predicted to } \\
\text { evolve }\end{array}$ \\
\hline Environmental disrupter & $\begin{array}{l}\text { It is not an evolved trait but enforced and thus occurs in all } \\
\text { environments }\end{array}$ \\
\hline Genetic differentiation & $\begin{array}{l}\text { Environmental variation between populations. Environment is } \\
\text { predictable for the individual. }\end{array}$ \\
\hline Developmental plasticity & $\begin{array}{l}\text { Re-occurring variation within populations which the individuals } \\
\text { can predict. }\end{array}$ \\
\hline Social flexibility & Non-predictable but re-occurring variation within populations. \\
\hline
\end{tabular}


If the environment is not predictable but differs significantly from generation to 300 generation, social flexibility enabling an adaptive response at a later life history stage and not 301 during early development should evolve. Social flexibility offers the potential to respond

302 immediately in a number of ways to changing environmental conditions. In most cases of 303 developmental plasticity, such as a response to prevailing predation pressure (Steiner \& 304 Buskirk 2008; Lind et al. 2015), there is no or only a very short time lag between the reliable 305 information and the fitness benefit of the alternative phenotype. In contrast, the time lag 306 between the juvenile stage and the breeding stage is often much longer. This could explain 307 why many examples exist of social flexibility explaining IVSO, but not for developmental 308 plasticity (Schradin, 2013). We therefore predict that developmental plasticity as the 309 mechanism for IVSO is most likely to occur in species where the juvenile and the breeding 310 life history stage follow shortly after one another. For example, in common voles (Microtus 311 arvalis), precocious fertile mating of non-weaned 14 days old females occurs (Tkadlec \&

312 Zejda 1995), being an extreme example of overlap between the juvenile and the breeding 313 stage. Future studies will have to test whether developmental plasticity is the mechanism

314 leading to IVSO in some species and whether this is related to a short time lag between 315 development and reproduction. In sum, all three adaptive mechanisms leading to IVSO are 316 predicted to have evolved as a response to environmental variation (Table 1).

\section{Testing predictions at the species level}

319 Testing for the adaptive value of IVSO requires a comparison of the fitness of individuals living in different types of social organizations under different environmental conditions. For example, male striped mice have alternative reproductive tactics, being either

322 the breeding males of communally breeding groups (called breeding males) or solitary 323 roamers attempting to copulate with females of several groups (Schradin et al. 2009). In 
324 striped mice, IVSO occurs within populations. Striped mice of both sexes live solitarily when

325 population density is low, but live in communally breeding groups when population density is

326 high. However, solitary roaming males occur even under high population densities (because

327 the sex ratio at birth is equal but there is only one breeding male per communal group), but

328 have a lower body mass (= competitive ability) than breeding males (Schradin et al. 2009).

329 Breeding males have 10 times higher reproductive success than roamers (Schradin \&

330 Lindholm 2011). However, when only roaming males occur, many of them have very high

331 reproductive success (Schradin \& Lindholm 2011). Importantly, under intermediate

332 population density, males (and also females) can be solitary or group-living, and the

333 reproductive success of roamers equals the reproductive success of breeding males (Schradin

334 \& Lindholm 2011). This indicates that IVSO in this species is the result of selection having

335 acted on individuals to maximize reproductive success.

336 If adaptive IVSO has been identified in a species, the main expectation would be that

337 the species showing IVSO lives in a variable environment (Table 1). In striped mice,

338 population density is the main predictor of social organization, determining whether

339 individuals live in groups or solitarily (Schradin et al. 2010; Schoepf \& Schradin 2012).

340 Population density is highly variable from year to year. This indicates that African striped

341 mice live in a variable and unpredictable environment, favoring the evolution of social

342 flexibility.

343 Statistically testing whether or not IVSO in a single species is due the variability in its

344 environment can be challenging. If genetic differentiation has been identified as the

345 mechanism of IVSO, one could measure selected environmental factors and compare these

346 between populations with social organization type A with populations showing the different

347 social organization type B. For this, an appropriate sample size is needed in the different

348 populations showing the two forms of social organization. If the identified mechanism is 
developmental plasticity, it could be shown statistically that the environmental factors are

350 predictable for the individuals by doing autocorrelations or other time series analyses.

351 Social flexibility is characterized by environmental factors that are unpredictable, such

352 that no significant autocorrelation of the factors determining social organization would be

353 expected. For example, the population density experienced as juveniles would not predict

354 (correlate with) the population density when the individual is breeding. Thus, the

355 environmental factor measured at time(breeding-x) does not predict the same factor at time(breeding),

356 which would be the case if an identified cycle (for example 7 years) does not correspond with

357 the life history cycle (e.g. 2 year) of a species, or if no cycles exist at all, indicating

358 environmental unpredictability that results in non-significant statistical relationships. This

359 would be statistically problematic as one would expect the null hypothesis to be true (the

360 variable factor cannot be predicted). There are no tests demonstrating unpredictability, but

361 there are statistical tools such as time series tests to detect structure in a dataset. This can be

362 applied to a time series of environmental data and the absence of any signal at the time scales

363 of the animal's lifetime would indicate that the variable is unpredictable for the individual of

364 this study period. Potential methods include wavelet analysis which generates complementary

365 wavelets with different periodicities to decompose data without gaps. The wavelets are then

366 used to detect periodicity in the environmental time series at different time scales. Another

367 approach is to use a test for autocorrelation (Moran's test, Portmanteau test's, Box-Pierce,

368 Ljung-Box Q test) to detect a structure in the time series (Diggle 1990).

369

370

371

372

373

374

\section{Testing predictions in comparative studies}

The comparative method relies on large datasets of many species. Comparative studies could be used to establish whether variation in key environmental factors such as rainfall and food availability or life history are associated with the occurrence of IVSO over a large number of species. There are three important issues we want to address about how to improve 
375 future comparative studies. First, despite evidence that IVSO has been observed in mammals

376 (Dalerum 2007; Valomy et al. 2015; Garber et al. 2016; Mann \& Karniski 2017), existing

377 databases on the social organization of mammals and other taxa typically do not consider

378 IVSO but assign one form of social organization to each species. Ignoring IVSO in

379 comparative studies can lead to spurious conclusions about social evolution (Silvestro et al.

380 2015; Sandel et al. 2016). For example, it was previously believed that social carnivores

381 evolved from a solitary ancestor, but taking IVSO into account indicated that the ancestor

382 might rather have been socially flexible (Dalerum 2007). Thus, it is crucial that IVSO is

383 considered in comparative studies of factors influencing social diversity in animals.

384 Second, to achieve maximum taxonomic breadth, some databases are populated with

385 information from the secondary literature and some data are based on the assumption that

386 closely related species have the same form of social organization, even if only one species has

387 been studied in detail. We advocate for a different approach in which scientists build a smaller

388 dataset based on the most reliable information from the primary literature (Schradin 2017) and

389 that includes IVSO (Valomy et al. 2015). Conclusions from comparative studies using high

390 quality primary data can differ significantly from comparative studies of large databases of

391 low quality data from the secondary and tertiary literature (Kappeler \& Fichtel 2016). For

392 example, one database for comparative studies included 90\% (399/445) of Eulipotphla in their

393 dataset with $>99 \%$ assigned a solitary social organization, often based on secondary literature

394 (Lukas \& Clutton-Brock 2013). In contrast, Valomy et al. (2015) using only primary literature

395 determined that reliable information was only available for 16 species, of which $56 \%$ of

396 species ( $\mathrm{n}=9 / 16)$ were social (living in pairs or in groups). Interestingly, IVSO was found in 7

397 Eulipotyphla species (Valomy et al. 2015). Detailed long-term studies can change our

398 understanding animal social systems even in well studied taxa (Elbroch et al. 2017).

399 Databases used in future comparative studies of IVSO and social evolution should be built

400 from data collected from the primary literature and not include assumptions about the social 
organization of an entire genus based on observations in a single or a few species (Schradin

402 2017). This will require that the social organizations of more species are studied in their

403 natural environment (Valomy et al. 2015; Schradin 2017).

404 Third, the next major challenge with comparative studies is the restriction of analyses

405 to adaptive forms of IVSO. This is difficult because environmental disrupters are a frequent

406 cause of non-adaptive IVSO. Thus, it would be beneficial if databases on the social

407 organization of a taxon do not only include whether IVSO occurs, but also whether it is

408 adaptive or non-adaptive. Unfortunately, this information is normally not available.

409

Predictions about the factors favouring the evolution of adaptive IVSO

\section{$411 \quad$ Table 2}

412 Predictions regarding IVSO to be tested in comparative studies.

\begin{tabular}{|c|c|}
\hline Hypothesis & Prediction \& mechanisms \\
\hline Non-adaptive & $\begin{array}{l}\text { IVSO is more common in species that are typically characterised by one } \\
\text { dominant breeding pair, indicating that environmental disrupters (death of } \\
\text { one dominant breeder) cause the observed variation. }\end{array}$ \\
\hline $\begin{array}{l}\text { Benefits under } \\
\text { environmental } \\
\text { heterogeneity }\end{array}$ & $\begin{array}{l}\text { IVSO occurs more frequently in species that occur in areas of the world } \\
\text { characterized by high inter-annual (among) year variation (coefficient of } \\
\text { variation) in rainfall and ambient temperature. This can for example induce } \\
\text { significant variation in population density and thus competition for } \\
\text { reproduction (and resources). } \\
\text { A positive relationship between IVSO and increasing diet breadth and greater } \\
\text { IVSO is expected in species found in regions with high within-year and inter- } \\
\text { annual variation in rainfall and food availability. }\end{array}$ \\
\hline $\begin{array}{l}\text { Benefits to short } \\
\text { lived species }\end{array}$ & $\begin{array}{l}\text { IVSO is more common in species with a short lifespan and that breed only for } \\
\text { one breeding season; these species are selected to respond optimally to the } \\
\text { prevailing environmental situation. }\end{array}$ \\
\hline $\begin{array}{l}\text { Responsiveness to } \\
\text { changing } \\
\text { environments over a } \\
\text { long lifetime }\end{array}$ & $\begin{array}{l}\text { IVSO is greater in species with long lifespans and that reproduce during } \\
\text { multiple years than species with short lifespans and that do not produce } \\
\text { offspring during multiple breeding seasons and that IVSO is positively } \\
\text { associated with habitat breadth. }\end{array}$ \\
\hline
\end{tabular}


414 The main prediction is that environmental factors important for fitness vary more in species

415 with than without IVSO (Table 2). Important factors are variation in rainfall and food 416 availability, which influence population density. Population density in combination with

417 resource availability can influence both the degree of competition within populations and the

418 extent to which ecological constraints limit reproductive and social options (Emlen 1982;

419 Koenig et al. 1992; Schradin 2013). Other environmental factors such as ambient temperature 420 and changes in predation pressure or parasite / infectious disease prevalence could also be 421 important for the evolution of IVSO.

The adaptive value of IVSO may depend on both environmental conditions and life history (Table 2). This is expected when environmental variation has different effects on longlived versus short-lived species and those with many versus few breeding attempts during a lifetime. Short-lived species will experience less environmental variation during a lifetime and thus must breed in the prevailing environment rather than wait to breed until the 427 environmental conditions have improved. If an individual of a short-lived species chooses a 428 reproductive and social tactic that leads to a comparatively low reproductive success during 429 its only breeding opportunity, its lifetime reproductive success will be below average. In 430 contrast, an individual of a long-lived species that breeds during many breeding seasons can 431 have a relatively high lifetime reproductive success even if its tactic leads to low success in 432 one breeding season. As an extreme example, consider a reproductive tactic that leads to very 433 high reproductive success during years in which multiple preferred foods are abundant but to 434 no reproductive success in years when food availability is restricted. In a long-lived species 435 where individuals breed in many years, this reproductive tactic could still be advantageous. 436 However, in a short-lived species where every generation breeds for only one year and is then 437 replaced by the next generation, individuals with this reproductive tactic would die without 438 having reproduced, resulting in a shift in the frequency of an alternative tactic. In sum, we 439 predict that IVSO is more likely to evolve in short-lived species, particularly species where 
440 individuals only breed during one single breeding season. This prediction should be compared

441 to the alternative prediction: long-lived species from heterogeneous environments evolved

442 IVSO as a tactic to cope with inter-annual variation in environmental conditions, thereby

443 using the best strategy for current conditions, while short-lived species are constrained to one

444 social tactic (Table 2).

445

446 Conclusions

447 The fact that a species shows IVSO is no evidence that it is an evolved trait of this species.

448 Environmental disrupters can be expected to cause IVSO even in species where IVSO is also 449 an adaptive response (Hill et al. 2015a; Hill et al. 2015b). Adaptive IVSO is expected to have 450 evolved in variable environments. To understand IVSO at the species level it is important to 451 conduct continuous long-term studies to differentiate between non-adaptive and adaptive 452 IVSO. In addition, it is necessary to measure variation in the environment, and statistical tools 453 such as time series analyses can be used test for structure in the data. One problem is that such 454 statistical analyses mainly demonstrate significant relationships such as cycles, but not non455 existing cycles, which would represent unpredictability. Thus, unpredictability is difficult to 456 demonstrate statistically, but an important factor for the evolution of social flexibility causing 457 IVSO.

458 IVSO is an important consideration when studying social evolution (evolution of 459 monogamy, cooperative breeding, paternal care, group versus solitary living), as not every 460 species can be assigned to one single form of social organization (Lott 1984; Lott 1991). For 461 such comparative studies, it is important to have reliable data based on the primary literature.

462 IVSO is an interesting phenomenon that needs scientific explanation. Understanding IVSO is 463 important because it demonstrates species resilience against environmental change and it can 464 help us to study ultimate and proximate reasons of group-living by comparing between 465 solitary and group-living individuals in a single species (Schradin et al. 2012). Finally, social 
organization can influence both social structure and mating system, but does not determine

467 these. Thus, once adaptive IVSO has been identified, future studies should investigate its

effects on social structure and mating system.

\section{Acknowledgments}

CS is thankful to Gustl Anzenberger who made him aware of the important mechanism of

472 environmental disruptor leading to non-adaptive IVSO. Studies in IVSO by CS were

473 supported by the Swiss National Science Foundation, the University of Zurich, Vontobel

474 Foundation, the Holcim Foundation, the Baumgarten Stiftung, the Helene-Bieber Fonds, the

475 University of Strasbourg Institute of Advanced Studies (USIAS) and the CNRS. LDH was

supported by National Science Foundation grant no. 1261026, a Summer Faculty Fellow

from the University of Tennessee at Chattanooga, and USIAS Visiting Scholar program.

\section{Literature cited}

Auld, J. R., Agrawal, A. A. \& Relyea, R. A. 2010: Re-evaluating the costs and limits of adaptive phenotypic plasticity. Proc. R. Soc. B-Biol. Sci. 277, 503-511.

Bendesky, A., Kwon, Y.-M., Lassance, J.-M., Lewarch, C. L., Yao, S., Peterson, B. K., He, M. X., Dulac, C. \& Hoekstra, H. E. 2017: The genetic basis of parental care evolution in monogamous mice. Nature 544, 434-439.

Berry, R. J., Tattersall, F. H. \& Hurst, J. 2008: Genus Mus. In: Mammals of the British Isles Handbook, 4th edn. (Harris, S. \& Yalden, D. W., eds). The Mammal Society, Southampton, U.K.

Burke, T., Davies, N. B., Bruford, M. W. \& Hatchwell, B. J. 1989: Parental care and mating behaviour of polyandrous dunnocks Prunella modularis related to paternity by DNA fingerprinting. Nature 338, 249-250.

Dalerum, F. 2007: Phylogenetic reconstruction of carnivore social organizations. Journal of Zoology 273, 90-97.

Davies, N. B. 1992: Dunnock Behaviour and Social Evolution. Oxford University Press, Oxford.

Davies, N. B., Hartley, I. R., Hatchwell, B. J. \& Langmore, N. E. 1996: Female control of copulations to maximize male help: a comparison of polygynandrous alpine accentors, Prunella collaris, and dunnocks, P. modularis. Animal Behaviour 51, 27-47.

Dickman, C. R., Greenville, A. C., Beh, C.-L., Tamayo, B. \& Wardle, G. M. 2010: Social organization and movements of desert rodents during population "booms" and "busts" in central Australia. J. Mammal. 91, 798-810.

Diggle, P. J. 1990: Time Series, A Biostatistical Introduction. Clarendon Press, Oxford. 
Dochtermann, N. A., Schwab, T. \& Sih, A. 2015: The contribution of additive genetic variation to personality variation: heritability of personality. Proceedings of the Royal Society B: Biological Sciences 282.

Ebensperger, L. A., Correa, L. A., León, C., Ramírez-Estrada, J., Abades, S., Villegas, Á. \& Hayes, L. D. 2016: The modulating role of group stability on fitness effects of group size is different in females and males of a communally rearing rodent. Journal of Animal Ecology 85, 1502-1515.

Eggert, A.-K. 1992: Alternative male mate-finding tactics in burying beetles. Behav Ecol 3, 243-254.

Elbroch, L. M., Levy, M., Lubell, M., Quigley, H. \& Caragiulo, A. 2017: Adaptive social strategies in a solitary carnivore. Science Advances 3.

Emlen, S. T. 1982: The evolution of helping. I. An ecological constraints model. Am Nat 119, 29-39.

Garber, P. A. 1997: One for all and breeding for one: cooperation and competition as a tamarin reproductive strategy. Evol Anthropol 3, 187-199.

Garber, P. A., Porter, L. M., Spross, J. \& Di Fiore, A. 2016: Tamarins: Insights into monogamous and non-monogamous single female social and breeding systems. Am. J. Primatol. 78, 298-314.

Gotzek, D. \& Ross, K. G. 2007: Genetic regulation of colony social organization in fire ants: An integrative overview. Quarterly Review of Biology 82, 201-226.

-. 2009: Current Status of a Model System: The Gene Gp-9 and Its Association with Social Organization in Fire Ants. PLOS ONE 4.

Hayes, L. D. \& Schradin, C. 2017: Long-term field studies in mammals: what the short-term study cannot tell us. J Mammal.

Hill, D. L., Pillay, N. \& Schradin, C. 2015a: Alternative reproductive tactics in female striped mice: heavier females are more likely to breed solitarily than communally. Journal of Animal Ecology 84, 1497-1508.

-. 2015b: Alternative reproductive tactics in female striped mice: Solitary breeders have lower corticosterone levels than communal breeders. Horm. Behav. 71, 1-9.

Hofmann, H. A., Beery, A. K., Blumstein, D. T., Couzin, I. D., Earley, R. L., Hayes, L. D., Hurd, P. L., Lacey, E. A., Phelps, S. M., Solomon, N. G., Taborsky, M., Young, L. J., Rubenstein, D. R., Nescent Working Group on Integrative Models of Vertebrate Sociality: Evolution, M. \& Emergent, P. 2014: An evolutionary framework for studying mechanisms of social behavior. Trends in Ecology \& Evolution 29, 581-589.

Hu, C. K. \& Hoekstra, H. E. 2017: Peromyscus burrowing: A model system for behavioral evolution. Seminars in Cell and Developmental Biology 61, 107-114.

Judge, P. G. 2000: Coping with crowded conditions. In: Natural conflict resolution. (Aureli, F. \& De Waal, F., eds). University of California Press.

Kappeler, P. M. \& Fichtel, C. 2016: The evolution of eulemur social organization. International Journal of Primatology 37, 10-28.

Kappeler, P. M. \& Schaik, C. P. v. 2002: Evolution of primate social systems. Int J Primatol 23, 707-740.

Keller, L. 2009: Adaptation and the genetics of social behaviour. Philos. Trans. R. Soc. Lond. B. Biol. Sci. 364, 3209-3216.

Koenig, W. D., Pitelka, F. A., Carmen, W. J., Mumme, R. L. \& Stanback, M. T. 1992: The evolution of delayed dispersal in cooperative breeders. Quart Rev Biol 67, 111-150.

Latham, N. \& Mason, G. 2004: From house mouse to mouse house: the behavioural biology of free-living Mus musculus and its implications in the laboratory. Applied Animal Behaviour Science 86, 261-289. 
Lind, M. I., Yarlett, K., Reger, J., Carter, M. J. \& Beckerman, A. P. 2015: The alignment between phenotypic plasticity, the major axis of genetic variation and the response to selection. Proceedings of the Royal Society of London B: Biological Sciences 282.

Lott, D. F. 1984: Intraspecific variation in the social systems of wild vertebrates. Behaviour 88, 266-325.

-. 1991: Intraspecific Variation in the Social Systems of Wild Vertebrates. Cambridge University Press, New York.

Löttker, P., Huck, M., Zinner, D. P. \& Heymann, E. W. 2007: Grooming relationships between breeding females and adult group members in cooperatively breeding moustached tamarins (Saguinus mystax). Am. J. Primatol. 69, 1159-1172.

Lukas, D. \& Clutton-Brock, T. H. 2013: The evolution of social monogamy in mammals. Science 341, 526-530.

Mann, J. \& Karniski, C. 2017: Diving beneath the surface: long-term studies of dolphins and whales. J. Mammal. 98, 621-630.

Markham, A. C. \& Gesquiere, L. R. 2017: Costs and benefits of group living in primates: an energetic perspective. Philosophical Transactions of the Royal Society B: Biological Sciences 372.

Martins, M. M., Nascimento, A. T., Nali, C., Velastin, G. O., Mangini, P. B., ValladaresPadua, C. B. \& Galetti Jr, P. M. 2015: A test for sex-biased dispersal in the blackfaced lion tamarin (Leontopithecus caissara): inferences from microsatellite markers. Studies on Neotropical Fauna and Environment 50, 14-20.

Mayer, M., Künzel, F., Zedrosser, A. \& Rosell, F. 2017: The 7-year itch: non-adaptive mate change in the Eurasian beaver. Behav Ecol Sociobiol 71, 32.

Meynard, C. N., Pillay, N., Perrigault, M., Caminade, P. \& Ganem, G. 2012: Evidence of environmental niche differentiation in the striped mouse (Rhabdomys sp.): inference from its current distribution in southern Africa. Ecology and Evolution 2, 1008-1023.

Milleret, C., Wabakken, P., Liberg, O., Åkesson, M., Flagstad, Ø., Andreassen, H. P. \& Sand, H. 2017: Let's stay together? Intrinsic and extrinsic factors involved in pair bond dissolution in a recolonizing wolf population. Journal of Animal Ecology 86, 43-54.

Müller, J. F., Braunisch, V., Hwang, W. \& Eggert, A.-K. 2006: Alternative tactics and individual reproductive success in natural associations of the burying beetle, Nicrophorus vespilloides. Behav Ecol 18, 196-203.

Nonaka, E., Svanbäck, R., Thibert-Plante, X., Englund, G. \& Brännström, Å. 2015: Mechanisms by which phenotypic plasticity affects adaptive divergence and ecological speciation. The American Naturalist 186, E126-E143.

Ometto, L., Shoemaker, D., Ross, K. G. \& Keller, L. 2011: Evolution of Gene Expression in Fire Ants: The Effects of Developmental Stage, Caste, and Species. Mol. Biol. Evol. 28, 1381-1392.

Phoenix, C. H., Goy, R. W., Gerall, A. A. \& Young, W. C. 1959: Organizing action of prenatally administered testosterone propionate on the tissue mediating mating behavior in the female guniea pig. Endocrinology 65, 369-382.

Piersma, T. \& Drent, J. 2003: Phenotypic flexibility and the evolution of organismal design. Trends in Ecology \& Evolution 18, 228-233.

Piersma, T. \& Gils, J. A. v. 2011: The flexible Phenotype. Oxford University Press, Oxford.

Porter, L. M., Hanson, A. M. \& Becerra, E. N. 2001: Group demographics and dispersal in a wild group of Goeldi`s monkeys (Callimico goeldii). Folia Primatol 72, 108-110.

Randall, J. A., Rogovin, K., Parker, P. G. \& Eimes, J. A. 2005: Flexible social structure of a desert rodent, Rhombomys opimus: philopatry, kinship, and ecological contraints. Behav Ecol 16, 961-973.

Reyer, H.-U. 1984: Investment and relatedness: a cost/benefit analysis of breeding and helping in the pied kingfisher (Ceryle rudis). Anim. Behav. 32, 1163-1178. 
602

603

604

605

606

607

608

609

610

611

612

613

614

615

616

617

618

619

620

621

622

623

624

625

626

627

628

629

630

631

632

633

634

635

636

637

638

639

640

641

642

643

644

645

646

647

648

649

650

651

652

Reyer, H. U. 1980: Flexible helper structure as an ecological adaptation in the pied kingfisher (Ceryle rudis rudis L.). Behav Ecol Sociobiol 6, 219-227.

Rymer, T., Pillay, N. \& Schradin, C. 2013: Extinction or survival? Behavioral flexibility in response to environmental change in the African striped mouse Rhabdomys. Sustainability 5, 163-186.

Sandel, A. A., Miller, J. A., Mitani, J. C., Nunn, C. L., Patterson, S. K. \& Garamszegi, L. Z. 2016: Assessing sources of error in comparative analyses of primate behavior: Intraspecific variation in group size and the social brain hypothesis. Journal of Human Evolution 94, 126-133.

Schoepf, I. \& Schradin, C. 2012: Better off alone! Reproductive competition and ecological constraints determine sociality in the African striped mouse (Rhabdomys pumilio). Journal of Animal Ecology 81, 649-656.

Schradin, C. 2013: Intraspecific variation in social organization by genetic variation, developmental plasticity, social flexibility or entirely extrinsic factors. Philos. Trans. R. Soc. B-Biol. Sci. 368.

Schradin, C. 2017: Comparative studies need to rely both on sound natural history data and on excellent statistical analysis. R. Soc. Open Sci. .

Schradin, C. \& Hayes, L. D. 2017: A synopsis of long-term field studies in mammals: achievements, future directions, and some advice J Mammal.

Schradin, C., König, B. \& Pillay, N. 2010: Reproductive competition favours solitary living while ecological constraints impose group-living in African striped mice. Journal of Animal Ecology 79, 515-521.

Schradin, C. \& Lindholm, A. K. 2011: Relative fitness of alternative male reproductive tactics in a mammal varies between years. Journal of Animal Ecology 80, 908-917.

Schradin, C., Lindholm, A. K., Johannesen, J., Schoepf, I., Yuen, C.-H., König, B. \& Pillay, N. 2012: Social flexibility and social evolution in mammals: a case study of the African striped mouse (Rhabdomys pumilio). Molecular Ecology 21, 541-553.

Schradin, C., Scantlebury, M., Pillay, N. \& König, B. 2009: Testosterone levels in dominant sociable males are lower than in solitary roamers: physiological differences between three male reproductive tactics in a sociably flexible mammal. Am Nat 173, 376-388.

Shultz, S., Opie, C. \& Atkinson, Q. D. 2011: Stepwise evolution of stable sociality in primates. Nature 479, 219-222.

Silvestro, D., Kostikova, A., Litsios, G., Pearman, P. \& Salamin, N. 2015: Measurement errors should always be incorporated in phylogenetic comparative analysis. Methods of Ecol Evol 6, 340-346.

Steiner, U. K. \& Buskirk, J. V. 2008: Environmental stress and the costs of whole-organism phenotypic plasticity in tadpoles. J. Evol. Biol 21, 97- 103.

Tinbergen, N. 1963: On aims and methods of ethology. Z Tierpsychol 20, 410-433.

Tkadlec, E. \& Zejda, J. 1995: Precocious Breeding in Female Common Voles and Its Relevance to Rodent Fluctuations. Oikos 73, 231-236.

Valomy, M., Hayes, L. D. \& Schradin, C. 2015: Social organization in Eulipotyphla: evidence for a social shrew. Biology Letters 11.

VanBuskirk, J. \& Steiner, U. K. 2009: The fitness costs of developmental canalization and plasticity. J. Evol. Biol 22, 852- 860.

West-Eberhard, M. J. 2003: Developmental Plasticity and Evolution. Oxford Uiversity Press, Oxford.

Zabel, C. J. \& Taggart, S. J. 1989: Shift in red fox, Vulpes vulpes, mating system associated with El Niño in the Bering Sea. Animal Behaviour 38, 830-838.

Zimmermann, T. D., Kaiser, S., Hennessy, M. B. \& Sachser, N. 2017: Adaptive shaping of the behavioural and neuroendocrine phenotype during adolescence. Proceedings of the Royal Society B: Biological Sciences 284. 
653

654 